\title{
TLS-FEM INTEGRATED STRUCTURAL DEFORMATION ANALYSIS ON THE BEAMLESS HALL AT NANJING, CHINA
}

\author{
J.W. Fang ${ }^{1}$, Z. Sun ${ }^{1 *}$, Y. R. Zhang ${ }^{1}$ \\ ${ }^{1}$ School of Architecture, Nanjing Tech University, Nanjing, China - (202061211026, sunzheng, 202061211044) @njtech.edu.cn
}

KEY WORDS: Brick Masonry, Vault, Deviation Analysis, Structural Simulation, Terrestrial Laser Scanning, Finite Element Method, Architectural Heritage

\begin{abstract}
:
A method integrating terrestrial laser scanning (TLS) and finite element modelling (FEM) is proposed in this study. It aims at assessing the structural deformation of a historic brick-masonry building, the Beamless Hall at Linggu Temple in Nanjing, China. The building was composed of a series of vaults and arches, the largest among whom spans over $11 \mathrm{~m}$. TLS (Z+F Imager5010X) was used to collect 3D point cloud with high density. Point slices and geometric feature computation (verticality) were employed to detect geometric displacement quantitatively and intuitively. FEM-simulation was based on an ideal 3D model ignoring geometric anomalies. Results show that the Beamless Hall has inherent structural defect owing to its asymmetric layout along the transverse axis. Computing geometric feature of point cloud is fast and intuitive to detect and show geometric deviation. Inferred by FEM-simulated results and TLS-based deviation analysis, the building's asymmetrical layout under self-weight is probably the main reason causing its structural deformation. Further developments include FEM based on as-built geometry, corrected materials parameters, and a comprehensive geometric deviation analysis.
\end{abstract}

\section{INTRODUCTION}

\subsection{Structural deformation analysis on historic masonry buildings}

Masonry structures are widespread over the world. Most historic structures are made of unreinforced materials such as stones, bricks and mortar. Masonry vaults and arches are typical to such structure. Assessing their structural behavior is crucial for preventive conservation and technical intervention. Multi-source information is needed and non-invasive methodology is favored. A lot of research efforts have been devoted to this field, among which accurate geometric survey, numerical modeling and non-destructive testing (NDT) are employed owing to their non-invasive attributes (Maione et al., 2018).

Terrestrial laser scanning (TLS) has been applied to geometric survey of architectural heritage for decades. Nowadays point cloud model with mm-level accuracy and resolution could be obtained following well-established guidance (Historic England, 2018). Such data provides sufficient details for deviation analysis and can output deviation maps through different operations. Computing the distance between a point cloud and reference primitives is a common approach (Bonali et al., 2014). It enables a fast and accurate assessment, but defining a best-fit primitive could be difficult. Another approach is simply comparing the formal anomalies of repeated components (Costa-Jover et al., 2019). Monitoring and assessing differential settlements of vaulted structure are also possible through point cloud comparison algorithms (Acikgoz et al., 2017).

Finite element (FE) is one of the most widely used approach in the realm of numerical modeling for historic masonry structure (Barazzetti et al., 2015; Clementi et al., 2016; Olmati et al., 2018). Finite element modeling (FEM) integrated with as-built 3D model obtained with TLS improve the results of mechanical simulation (Almac et al., 2016; Korumaz et al., 2017). Although many commercial FEM programs are available, numerical modeling of unreinforced historic masonry structure is still an open issue considering geometry of 3D model, material parameters, and deterioration effects. In general, the geometry of a 3D model as input for FEM could be divided into three categories: continuum macro-modeling (one-phase material), simplified micro-modeling (two-phase material), and detailed micro-modeling (three phase material) (Asteris, 2015). In a detailed micro-modeling approach, brick units and mortar are distinguished, and give rise to the most accurate simulation of the behavior of masonry structures, but modelling computational efforts also rise accordingly. Hence it is wise to adopt a reasonable modeling approach given the characteristics of the studied building.

\subsection{The Beamless Hall at Linggu Temple}

The studied building, the Beamless Hall at Linggu temple, is located at Nanjing, China (figure 1). The Beamless Hall is believed to be built as a Buddhist temple in the $14^{\text {th }}$ or $15^{\text {th }}$ century (Liu, 1980). The volume of the building is pierced by a series of barrel vaults and arches made of bricks and mortar. Along the longitudinal axis there are three $40 \mathrm{~m}$-long parallel spaces spanned by three barrel vaults. The dominating central vault (CVT) has a span over $11 \mathrm{~m}$, one of the largest among similar brick-masonry vaulted structures built in the next few centuries in China. Standing on the south and north of CVT are two smaller barrel vaults (the south one: SVT; the north one: NVT). The Beamless Hall is subject to a set of pathologies including material weathering, crack, and structural deformation. Lateral displacement of CVT is even detectable by naked eye. A detailed geometric survey along with structural simulation are essential for daily monitoring and proposing restoration plans. 


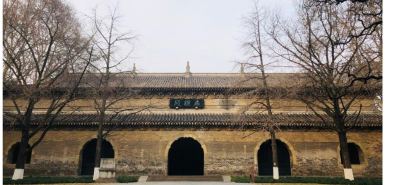

(a)

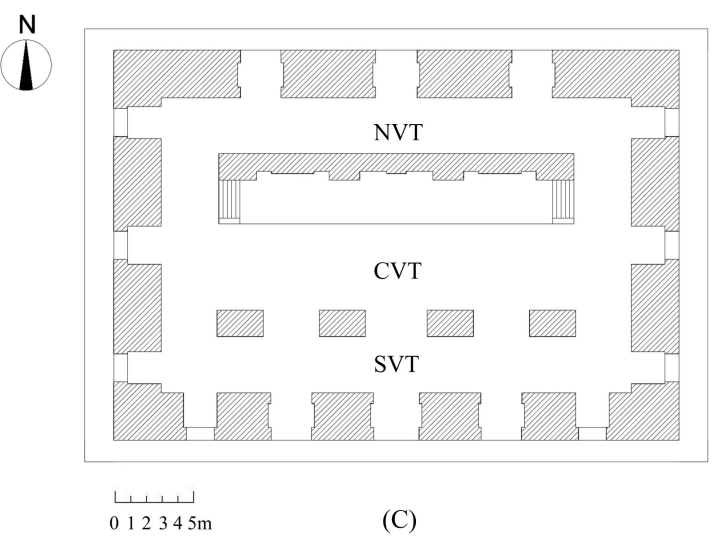

Figure 1. The Beamless Hall at Linggu Temple: (a) exterior view; (b) interior view; (c) floor plan.

\subsection{Aims of the study}

This research aims at assessing the structural deformation of the Beamless Hall at Linggu Temple by integrating TLS and FEM. The impact of the vaults' thrust on lateral displacement is analyzed geometrically and mechanically. The results are supposed to provide reference for monitoring and restoration.

\section{METHOD}

\subsection{Geometric survey}

A TLS-based survey (laser scanner Z+F Imager 5010X) was conducted to collect 3D point cloud from 63 scan-stations covering both interior and exterior (figure 2). These scans were registered based on natural features of the building. The registration has an average error below $2 \mathrm{~mm}$. As the used laser scanner is phase-based, it allows a very dense points collection at $\mathrm{mm}$ level. A photogrammetric survey was also carried out to retrieve the color and texture of the building surface for visualizing purposes.

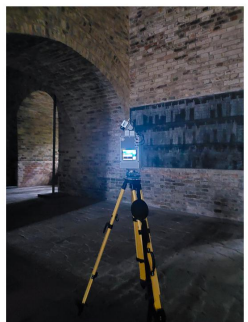

(a)

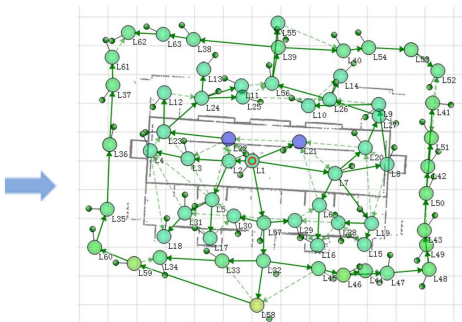

(b)
Figure 2. TLS-based survey for the Beamless Hall. (a) field survey with a Z+F Imager 5010X laser scanner. (b) spatial distribution of 63 scan-stations.

\subsection{FEM-based structural simulation}

A 3D solid model was established to simulate the structural behavior of the building under self-weight. The model was manually made in a commercial program Rhinoceros 6 based on TLS-derived point cloud and earlier survey (Pan, 2009). It is straightforward to generate the floor plan from the extracted cross section of the point cloud. The walls' displacement near the ground level is trivial compared to that at the level of the springing. Hence the 3D geometry of the walls was defined by extruding their footprints. The differential settlements of the vaults and arches were also neglected. Their cross sections were defined as semi-circles according to (Pan, 2009) and TLS-measurement. Although uncertainties exist during this process, their impact on structural simulation is limited.

A macro-modeling approach without distinction between individual brick units and mortar in the joints is used for FEM. The material parameters (table 1) of the building were quoted from an earlier study which employed destructive testing on another brick-masonry vaulted temple built in the $16^{\text {th }}$ century, China (Chun et al., 2019). The structural simulation was conducted in a commercial program ANSYS Workbench 19.0. Only self-weight acting as a dead load was considered. The element size of FEM was set to $100 \mathrm{~mm}$.

\begin{tabular}{ccccc}
\hline $\begin{array}{c}\text { Density } \\
\left(\mathrm{kg} / \mathrm{m}^{3}\right)\end{array}$ & $\begin{array}{c}\text { Young's } \\
\text { Modulus } \\
(\mathrm{MPa})\end{array}$ & $\begin{array}{c}\text { Poisson's } \\
\text { Ratio }\end{array}$ & $\begin{array}{c}\text { Bulk } \\
\text { Modulus } \\
(\mathrm{MPa})\end{array}$ & $\begin{array}{c}\text { Shear } \\
\text { Modulus } \\
(\mathrm{MPa})\end{array}$ \\
\hline 1990 & 3.024 & 0.15 & 1.44 & 1.138 \\
\hline \multicolumn{5}{c}{ Table 1. Material parameters for FEM. }
\end{tabular}

\subsection{Deviation analysis}

Extracted cross-sections from point cloud are widely used to reveal structural deformation, but it fails to show a global deformation trend (i.e. a deviation map). A point-primitive distance computation caters to this purpose, but determining the shape of primitive requires extensive studies. A fast and intuitive way was used to produce deviation map of the walls supporting the vault in this research. It integrated point slices with verticality, a geometric feature of point cloud.

The point slices of the building were extracted in CloudCompare (Girardeau-Montaut, 2018) with a width of $1 \mathrm{~cm}$ Two different sampling density were used: $10 \mathrm{~cm}$ to show deformation trend of the whole building, and $2 \mathrm{~cm}$ to reflect deformation locally. Geometric feature (i.e. planarity, sphericity, verticality) of a point cloud model describe the shape as a combination of the eigenvalues $(\lambda 1>\lambda 2>\lambda 3)$ extracted from the covariance matrix (Blomley et al., 2014). Verticality was computed in this study to show the deformation of walls owing to lateral forces.

The longitudinal walls under SVT, CVT, and NVT were manually segmented. Their verticality was computed with a radius of $0.4 \mathrm{~m}$ in CloudCompare. Such a radius is appropriate to reflect their lateral displacement considering the building's dimension and the deformation degree.

\section{RESULTS}

\subsection{Stress distribution and deformation risk based on FEM}

FEM-simulated results show that the stress distribution and structural deformation pattern of the Beamless Hall under self-weight is not symmetrical along the transverse axis.

1. The largest tensile stress is distributed on the central northern surface of SVT (figure $3 a$ and $3 b$ ). 
2. Compressive stress vary dramatically below the openings on the transverse exterior walls (figure $3 \mathrm{c}$ ). The existence of cracks should be checked in such areas, and closely monitored.
3. The largest deformation risk is located at the southern surface of CVT (figure 3d). A S-shape distortion of the wall under CVT is relevant to such deformation trend.
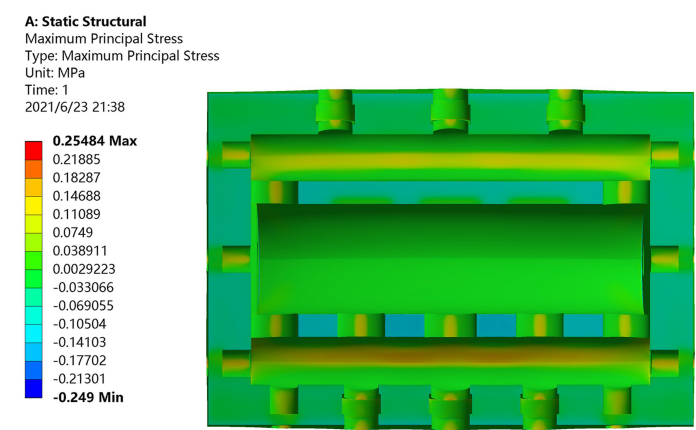

(a)

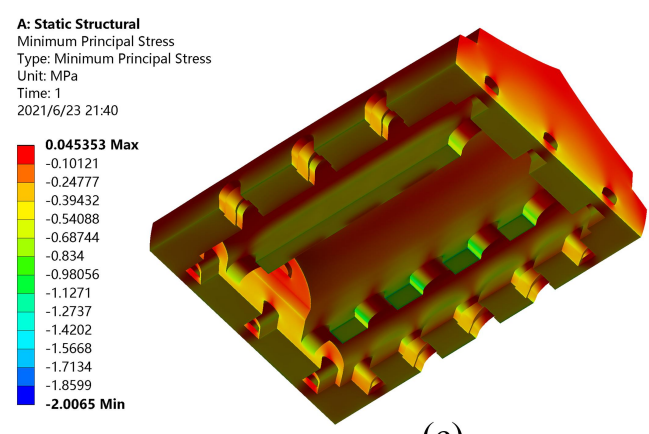

(c)

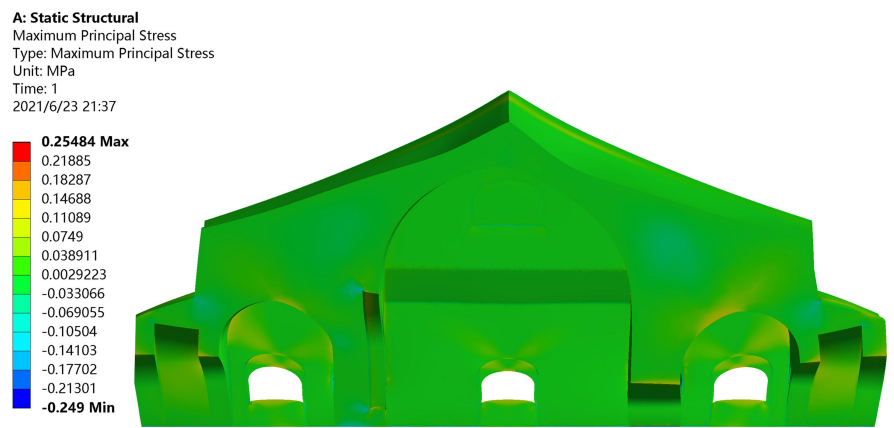

(b)

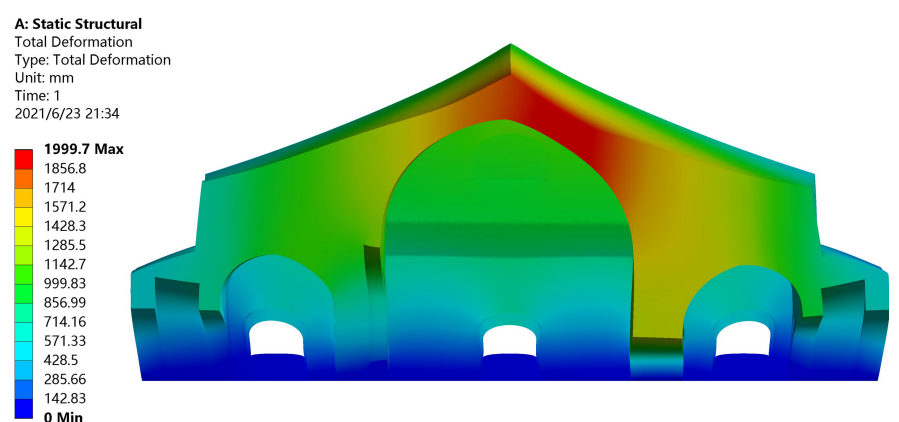

(d)

Figure 3. FEM-based structural simulation. The distribution of maximum principle stress (tensile stress) in extrado view (a) and transverse section view (b); (c) the distribution of minimum priciple stress (compressive stress); and (d) the distribution of deformation risk.

\subsection{Deviation analysis based on TLS}

The geometric deformation of the Beamless Hall was analysed based on point slices and computed verticality.

1. The vertically extracted points show that the major deformation occurs along the transverse axis. SVT, CVT, and NVT are subject to apparent lateral displacements at the level of the springing of the vault owing to the vaults' thrust (figure 4a). Such displacement reaches its maximum at the center of the vaults as horizontally extracted point slices show (figure $4 b$ ).

2. A S-shape distortion is observed at the south wall under CVT (figure 5). It is probably due to the interacted thrust between SVT and CVT. The former thrust lead to a lateral displacement $(\mathrm{ca} .10 \mathrm{~cm})$ around the springing of SVT, and the latter lead to a reverse displacement (ca. $15 \mathrm{~cm}$ ) around the springing of CVT.

3. The computed 'verticality' of the six pieces of longitudinal wall show that the south walls are subject to more severe distortion than the north walls. A southward deformation trend is observed in the longitudinal walls under vaults SVT, CVT, and NVT as their chromatically-scaled verticality show (figure 6).

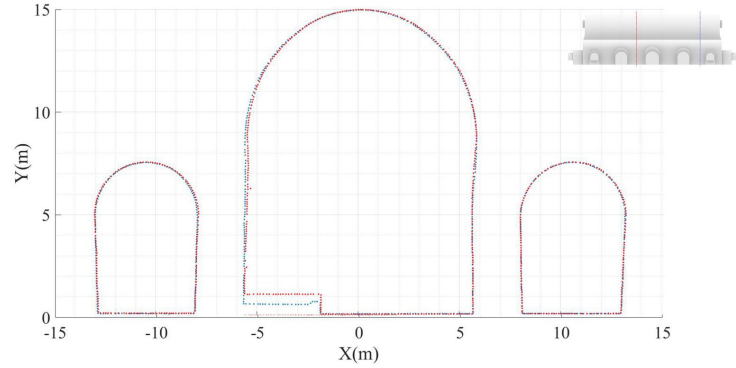

(a)

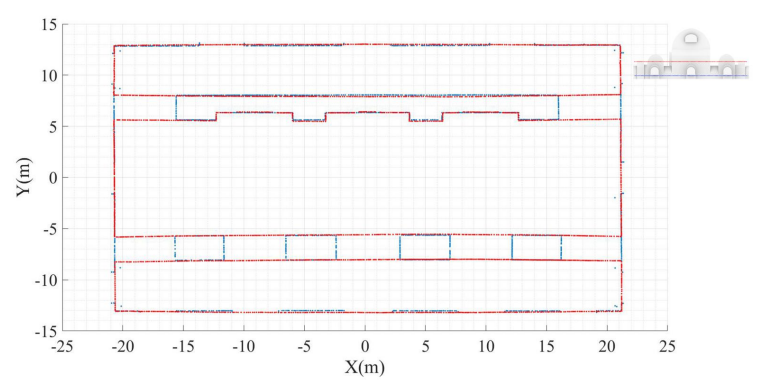

(b)

Figure 4. Extracted point slices. (a) transverse section; (b) floor plan. 


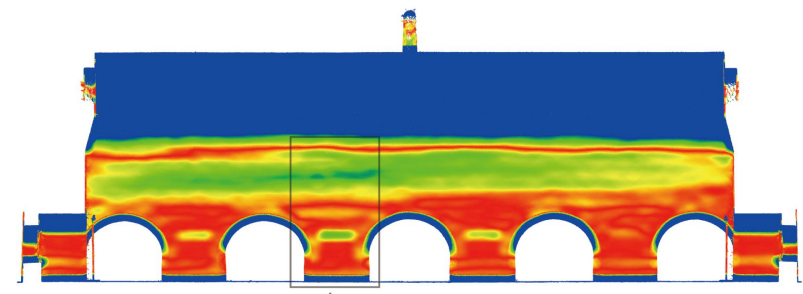

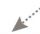

(a)

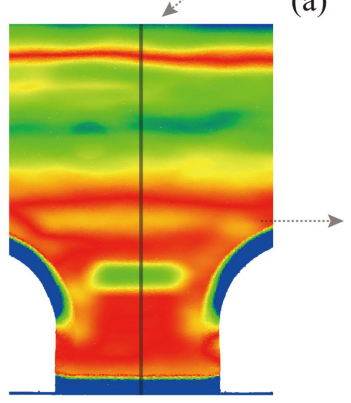

(b)

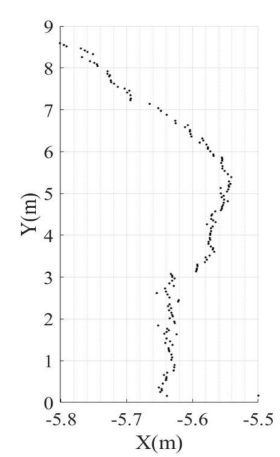

(c)

Figure 5. Analyzing the lateral displacement of the south wall under CVT. Chromatically scaled point cloud globally (a) and

locally (b); and (c) a point slice with S-shape distortion.

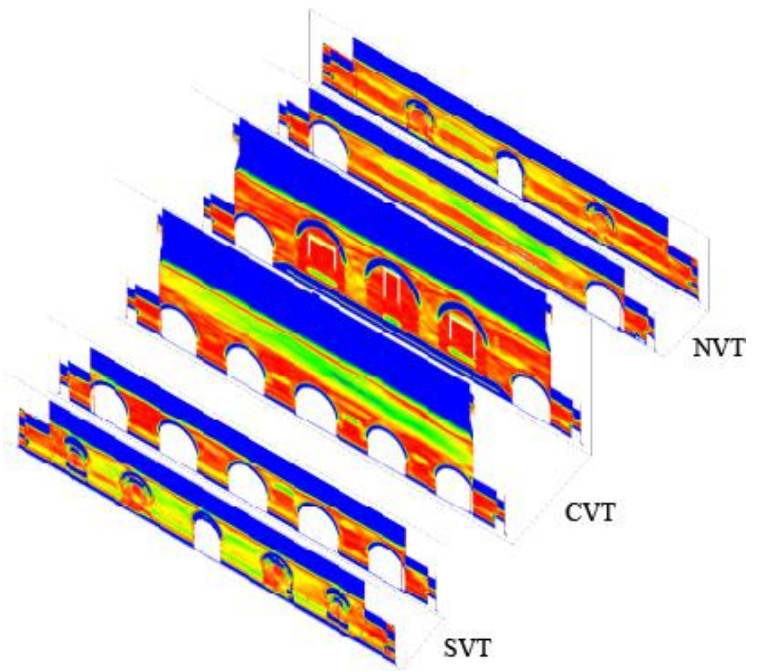

Figure 6. The longitudinal walls under vaults SVT, CVT, and NVT chromatically scaled according to computed geometric feature (verticality, radius $=0.5 \mathrm{~m})$.

\section{DISCUSSION}

The studied building represents a unique architectural type in Chinese history. Since the $15^{\text {th }}$ century, vaulted brick-masonry structure started to appear in urban infrastructures and civil engineering in China. The Beamless Hall at Linggu Temple as one of the earliest and most complex remains is an important case in this realm. Existing studies on Chinese historic vaulted structures have been made from the viewpoints of cultural spread and descriptive geometry (Chang, 1993, 1991; Wang, 1987). Recent studies focus on their structural behavior (Chun et al., 2019). This study poses a perspective from numerical modeling integrated with geometric deviation analysis. It aims at understanding the structural behavior of the building, especially the dominating barrel vault (CVT) spanning over $11 \mathrm{~m}$. FEM-simulated results show a southward deformation trend of CVT under self-weight. TLS-based deviation analysis,

both computed geometric feature and point slices, support this simulation result. Although further studies (e.g. NDT) would elaborate the numerical modeling, we deem at this phase that asymmetrical layout under self-weight is the main reason causing the building's local severe lateral displacement. The three vaults' interactive thrust along the transverse axis lead to movements on their supporting walls. Although SVT and NVT have similar dimensions in terms of span and height, the south wall under CVT was penetrated by five vaults, while the north by only two. Asymmetry also exists on the longitudinal exterior walls penetrated by different amounts of opening (three openings on the north wall under NVT and five under the south wall under SVT) (figure 1c). TLS-based deviation analysis is in accordance with the FEM-simulated results in two aspects: 1) a global southward deformation trend (figure 6); 2) S-shape distortion of the south wall under CVT (figure $5 \mathrm{c}$ ). Understanding this structural behavior is crucial to making decisions for technical intervention. The compressive stress distribution highlighted in FEM show varying stress at the corner of openings on the transverse exterior walls. Cracks were found in such areas (figure 7) and should be under close monitoring.

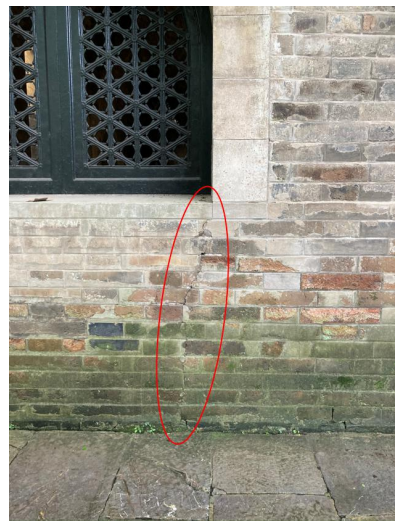

Figure 7. A crack under an opening of the exterior transverse wall.

It should be noted that the application of FEM-simulation in this study is preliminary. Workmanship, material deterioration, and historic consolidation (the use of reinforced-concrete and cement in 1930s) (Pan, 2009) may also affect the structural behavior of the building. An ideal 3D model ignoring geometric anomalies was employed in this study, but as-built irregular geometry could be relevant to local stress concentration. Bricks and mortar were considered as homogeneous material without distinguishing the units and joint. These issues should be considered in further studies. A detailed as-built model with elaborated material parameters would improve the simulation results.

The geometric analysis integrating local point slices with global verticality is fast, effective and intuitive. Computing verticality eases the burdens and potential errors of defining reference plane to which the point clouds is compared, and gives rise to intuitive impression of the deformation areas and extent with textured mesh obtained with photogrammetry (figure 8). Amateurs could understand the structural issues of the building through augmented reality on smart phone. A comprehensive study on the vaults' lateral displacement at springing will be developed in the future. The differential settlement of vaults will also be studied by integrating point slices with geometric features (e.g. sphericity). 


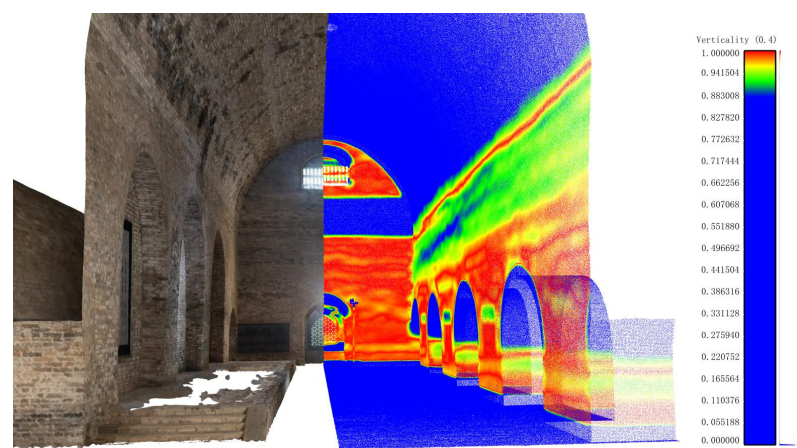

Figure 8. Visual of the deformation areas. The color scale was obtained by calculating the 'verticality' of point cloud (radius $=0.4 \mathrm{~m})$.

\section{CONCLUSIONS}

An integrated non-invasive method was adopted in this study to analyze the structural deformation of a historic brick-masonry building, the Beamless Hall at Linggu Temple. FEM simulated the building's structural deformation under self-weight, and shows risky areas in terms of deformation trend. Point slices and geometric feature of TLS-derived point cloud was used for geometric deviation analysis. Results show that the Beamless Hall has inherent structural defect owing to its asymmetric layout along the transverse axis. Geometric feature of point cloud is fast and intuitive to detect and show geometric deviation.

FEM-based on as-built geometry, corrected material parameters detected by NDT and a comprehensive geometric analysis would elaborate this study in the future.

\section{ACKNOWLEDGEMENTS}

This study was funded by the National Natural Science Foundation of China (51708285), the Natural Science Foundation for Higher Education of Jiangsu (20KJB560001) and National First Class Undergraduate Courses (Historic Building Survey).

\section{REFERENCE}

Acikgoz, S., Soga, K., Woodhams, J., 2017. Evaluation of the response of a vaulted masonry structure to differential settlements using point cloud data and limit analyses. Co nstruction and Building Materials 150, 916-931. https://doi. org/10.1016/j.conbuildmat.2017.05.075

Almac, U., Pekmezci, I.P., Ahunbay, M., 2016. Numerical Analysis of Historic Structural Elements Using 3D Point Cloud Data. TOBCTJ 10,233-245. https://doi.org/10.2174/18 74836801610010233

\section{Ansys ${ }^{\circledR}$ WorkBench, Release 19.0.,2018.}

Asteris, P., 2015. Numerical modeling of historic masonry structures, in: Handbook of Research on Seismic Assessme nt and Rehabilitation of Historic Structures. IGI Global, p p. 213-256.

Barazzetti, L., Banfi, F., Brumana, R., Gusmeroli, G., Prev itali, M., Schiantarelli, G., 2015. Cloud-to-BIM-to-FEM: St ructural simulation with accurate historic BIM from laser $\mathrm{s}$ cans. Simulation Modelling Practice and Theory 57, 71-8 7.

Blomley, R., Weinmann, M., Leitloff, J., Jutzi, B., 2014. S hape distribution features for point cloud analysis \&ndash; a geometric histogram approach on multiple scales. ISPR S Ann. Photogramm. Remote Sens. Spatial Inf. Sci. II-3, 9-16. https://doi.org/10.5194/isprsannals-II-3-9-2014

Bonali, E., Pesci, A., Casula, G., Boschi, E., 2014. Defor mation of Ancient Buildings inferred by Terrestrial Laser Scanning methodology: the Cantalovo church case study (Northern Italy): Deformation of ancient buildings inferred by TLS methodology. Archaeometry 56, 703-716. https:// doi.org/10.1111/arcm.12028

Chang, Q., 1991. On the origin of brick and stone vaulted structures in the Han Dynasty. Studies in the History of Natural Sciences 10, 288-295.

Chang, Q., 1993. On the evolution of ancient Chinese bric $\mathrm{k}$ and stone vaulted buildings in the Yuan and Ming Dyna sties. Studies in the History of Natural Sciences.12, 192-2 00 .

Chun, Q., Yang, H., Meng, Z., Han, Y., 2019. Research o $\mathrm{n}$ the architectural form and structural performance of the brick - vault hall of Yongzuo Temple. Sciences of Conserv ation and Archaeology 31, 85-91.

Clementi, F., Gazzani, V., Poiani, M., Lenci, S., 2016. Ass essment of seismic behaviour of heritage masonry building $\mathrm{s}$ using numerical modelling. Journal of Building Engineer ing 8, 29-47. https://doi.org/10.1016/j.jobe.2016.09.005

Costa-Jover, A., Lluis i Ginovart, J., Coll-Pla, S., López P iquer, M., 2019. Using the terrestrial laser scanner and si mple methodologies for geometrically assessing complex m asonry vaults. Journal of Cultural Heritage 36, 247-254. https://doi.org/10.1016/j.culher.2018.10.003

Girardeau-Montaut, D., 2018. Cloudcompare-open source pr oject.

Historic England, 2018. 3D Laser Scanning for Heritage: Advice and Guidance on the Use of Laser Scanning in Ar chaeology and Architecture. Historic England, Swindon.

Korumaz, M., Betti, M., Conti, A., Tucci, G., Bartoli, G., Bonora, V., Korumaz, A.G., Fiorini, L., 2017. An integrate d Terrestrial Laser Scanner (TLS), Deviation Analysis (DA) and Finite Element (FE) approach for health assessment of historical structures. A minaret case study. Engineering Structures 153, 224-238. https://doi.org/10.1016/j.engstruct.2 017.10 .026

Liu, D., 1980. The building era and style souce of Beaml ess hall at Linggu Temple, Nanjing-a letter on an issue of Chinese architectural history. Architectural history and the ory 1 .

Maione, A., Argiento, L.U., Casapulla, C., Prota, A., 2018. Management of multi-source information to identify the $t$ ypology of the horizontal structures in historical masonry buildings: the case study of the Museum of Capodimonte in Naples (Italy). Frattura ed Integrità Strutturale 12, 240 -251. https://doi.org/10.3221/IGF-ESIS.46.22

Olmati, P., Gkoumas, K., Bontempi, F., 2018. Simplified F EM modelling for the collapse assessment of a masonry $\mathrm{v}$ 
The International Archives of the Photogrammetry, Remote Sensing and Spatial Information Sciences, Volume XLVI-M-1-2021 28th CIPA Symposium “Great Learning \& Digital Emotion”, 28 August-1 September 2021, Beijing, China

ault. Frattura ed Integrità Strutturale 13, 141-149. https:// doi.org/10.3221/IGF-ESIS.47.11

Pan, G., 2009. History of Ancient Chinese Architecture, $2 n$ $d$ ed, Volume 4. China Architecture Publishing.

Wang, Q., 1987. The basic form of vault geometry in the Qing Dynasty. Traditional Chinese architecture and garde ns 5(2). 53-55 